\title{
A STUDY ON THE CRACK GENERATION IN FILL-TYPE DAMS
}

\author{
Kunitomo Narita* and Yoshio Ohne**
}

\begin{abstract}
Cracks occuring on the surface or internal parts of fill-type dams have been a matter of great concern for dam engineers, because such cracks sometimes induce internal piping and lead to catastrophic damages of dams. In this paper, the problem of transverse cracks caused by the differential settlements in the longitudinal sections of high embankments is discussed through analytical investigations, and some considerations are given on effective methods for estimating and controlling cracks in the practical design and construction. Numerical analyses are performed by the finite element method assuming that the material is linearly elastic. In the present paper, correlations between the transverse cracks and the configuration of abutment surfaces such as the sharp change of the inclination are first clarified. In practical application of the finite element solutions, it is shown that these are very effective for the prediction of the cracking potential in actual dams. On the basis of above conclusions, a practical method of assessing the possibility of crack generation is proposed taking the tensile strain as a criterion.
\end{abstract}

Key words: dam, finite element method, settlement, strain, tension IGC: $\quad \bar{E} 1 / \mathrm{E} 2$

\section{INTRODUCTION}

It has often been reported that harmful cracks sometimes take place on the surface or internal parts of high embankments such as earth and rockfill dams due to the settlements during and after construction. Such cracks induce leakage or piping when a reservoir is fully impounded, and in extreme cases they lead to subsequent damages or failures.

As cracks occuring in fill dams are believed to have their direct causes principally on the differential settlements in embankments or on the relative settlements between the zoned sections, some indirect causes which produce such settlements are enumerated as follows:

a) the configuration of abutment surfaces and core trenches: i.e., steep slopes, the existence of cliffs and overhangs and sharp change of the inclination.

b) the existence of highly compressible materials in embankments or on foundations.

c) discontinuities in the compressibility of core and shell materials.

d) physical and mechanical properties of fill materials and placement conditions (Fig. 1).

As cracks in actual dams take place under complex situations, it is very difficult to identify which cause is the most influential. The practical methods of controlling cracks. have been proposed, therefore, not only for the purpose of eliminating individual causes, but also on the basis of all-inclusive and experiential viewpoints. These are, for example, a) foundation treatments: to remove or to fill irregular abutment surfaces and to excavate

* Associate Professor, Department of Civil Engineering, Aichi Institute of Technology, Toyota, Aichi. ** Professor, ditto.

Written discussions on this paper should be submitted before January 1, 1979. 
compressible river bed deposit, b) to incline the core zone upstream or to widen the outer shell zones for limiting the relative settlements, c) to curve the axis of the dam slightly upstream for expecting the increase in compressive stress in the core, d) to place thin clayey layer in high water content between the core and the abutment rock for expecting the improvement of the core contact condition. Since most of these methods are based on rather experiential considerations, their effects have not been made clear so sufficiently as to be evaluated quantitatively.

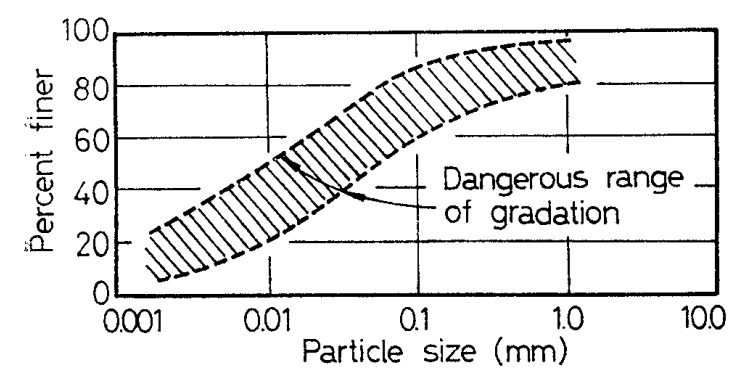

Fig. 1. Range of cracky materials (after Sherard et al., 1963)

The problems on the crack generation were firstly reviewed by Sherard et al. (1963), in which they presented that cracks occuring in actual dams were correlated to the physical properties of fill materials and to the placement conditions, as shown in Fig. 1. Subsequent studies have showed some theoretical and experimental approaches on this problem. Based on the theory of elasticity, Leonards and Narain (1963) gave two analytical methods of estimating tensile strains developing along the crest of dams when surface settlement curves were known. Theoretical solutions were then applied to actual dams and the results were compared with the tensile strains at cracking obtained by field observations and by beam tests conducted on the same fill materials. Lee and Shen (1969) pointed out the importance of understanding the relationship between the vertical subsidence and horizontal movements, and interpreted post-construction deformations in the upper portion of embankments by comparing it to the phenomenon of beam bending. Tensile strains along the crest were evaluated by a simplified beam theory and compared with the finite element solutions and the observed strains. In the above two studies, it was concluded that, though some errors were unavoidable, proposed simplified theoretical approaches were reasonable to some extent of accuracy and satisfactory for practical applications.

Covarrubias (1969) carried out two-dimensional finite element analyses on embankments having various longitudinal and transverse sections and examined the cracking phenomenon principally from qualitative viewpoints. Instead of having set up many situations, however, his discussions were somewhat short of description on the correlation between cracks and the shape of abutments. Eisenstein et al. (1972) studied the problem taking non-linear material properties into account and discussed two- and three-dimensional stress distributions in embankments. They showed that both incremental loading and non-linearity decreased the extent of the tension zone as compared with linear single lift solutions and that significant differences arose between two- and three-dimensional solutions when the properties of the core differed from the shell material. Because their discussions were concerned only with the behaviours of dams during construction, post-construction stress and strain distributions which are closely connected with cracking of fill dams have not yet been made clear.

This paper discusses the problem of transverse cracks caused by the post-construction differential settlements in the longitudinal section of fill dams. Cracks which take place during construction are not examined in the present study, because most of these cracks would disappear due to the running of construction equipments and, therefore, they are in general of less importance in the cracking problem. Numerical analyses are performed by the finite element method and some considerations are given on correlations between transverse cracks and the shape of abutments. Applicability of finite element solutions to practical problems is then examined for a few actual dams. Finally, based on the former 
discussions, a practical method of assessing the possibility of crack generation is proposed.

\section{CORRELATIONS BETWEEN CRACKS AND ABUTMENT CONFIGURATION}

\section{Analytical Procedure}

In this section, some theoretical considerations are given on the correlations between transverse cracks which develop in the longitudinal section of fill dams and the shape of valleys or core trenches. Analyses are conducted by the finite element method on the assumptions that the dam is in plane strain deformation condition and is constructed of homogeneous, isotropic, elastic material.

Analyses of embankment stresses and deformations are usually performed in two manners: one is called the single lift procedure and the other the incremental loading procedure. The discrepancy in these analytical results arises mainly in the distribution of vertical displacement (Clough and Woodward, 1967). The single lift vertical displacements show maximum value at the top as a result of vertical strains of full layers being accumulated. On the other hand, the incremental loading analysis gives maximum value at midheight and zero displacement at the top.

Post-construction settlements may consist principally of those due to consolidation and those at reservoir filling. Compressive strains of layers would develop in the former case due to the increase in effective stress on dissipating porewater pressure, and in the latter due to the change of soil structure on wetting. Because the accumulation of such compressive strains results in the crest settlement, the single lift solutions appear to represent settlements and other deformations developing after construction. The single lift procedure was therefore adopted in the present investigation.

Finite element model used in the present computation was arranged in ten horizontal layers. It is assumed, moreover, that both vertical and horizontal displacements are zero on the base of the dam and on the abutment surface. In the following, the height of the dam, half of the crest length and the length of horizontal projection of the abutment are denoted by $H, B$ and $C$, respectively.

In elastic analyses in which the loading results from gravitational body forces, three quantities, the unit weight $\gamma$ and Young's modulus $E$ of the embankment material and a standard length such as the height of the dam $H$ can be taken out from the stiffness equation. Accordingly, all solutions of displacements, strains and stresses can be normalized in numerical computations taking these quantities as $1.0:$ normalized solutions are $u /\left(\gamma H^{2} / E\right), \varepsilon /(\gamma H / E)$ and $\sigma / \gamma H$, respectively. However, Poisson's ratio $\nu$ is isolated in such a treatment and has to be specified separately. Poisson's ratio is assumed to be 0.3 in the following computations refering to some data from experiments and field observations (Narita, 1976). The influence of this parameter will be discussed later.

\section{Numerical Computation Results}

Fig. 2 shows the distributions of horizontal and vertical displacement $u, w$ and horizontal strain $\varepsilon_{x}$, along the crest of dams constructed in trapezoidal valleys having a constant width $B / H=2.5$ and different abutment slopes : each horizontal strain curve is given by differentiating corresponding curve of horizontal displacement. The characters existing in these curves are a) the direction of the horizontal displacement $u$ is towards the point of maximum settlement $w_{\max }$ and $u=0$ at $w=w_{\max }$, b) $u=u_{\max }$ and $\varepsilon_{x}=0$ at the point of steepest slope of the settlement curve, c) $\varepsilon_{x}$ shows maximum value at the point of steepest slope of the horizontal displacement curve and d) $\varepsilon_{x}$ is compressive over the central part of the settlement curve and tensile in outer zones. Similar pattern has also been noticed by Lee and Shen (1969).

Relations of the maximum tensile strain $\left(\varepsilon_{x}\right)_{\max }$ developed on the crest and the extent 


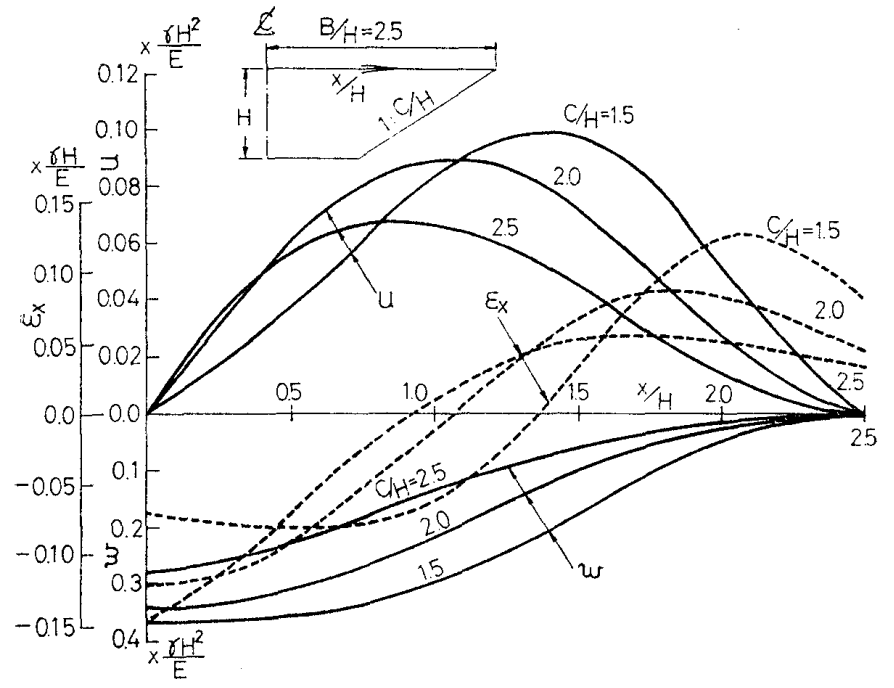

Fig. 2. Three movement curves along the crest of dams constructed in trapezoidal valleys $(\boldsymbol{B} / \boldsymbol{H}=\mathbf{2 . 5})$

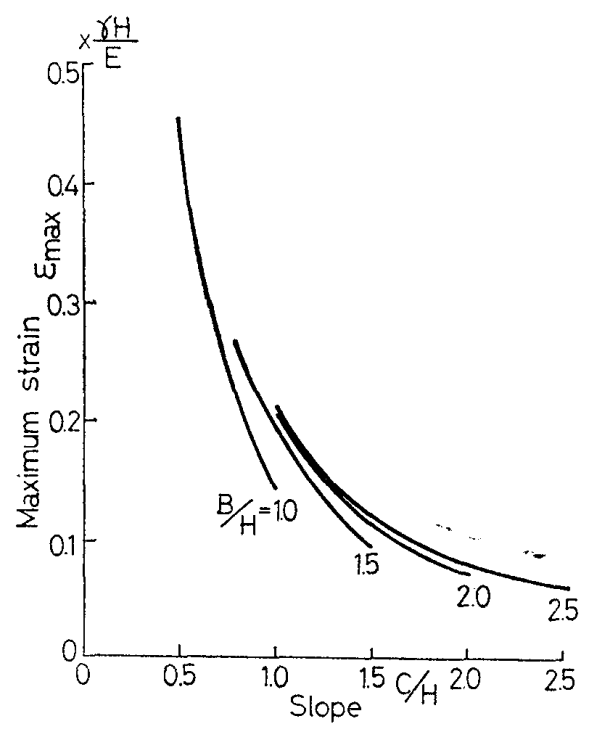

Fig. 4. Relation between maximum horizontal strain and the inclination of the abutment

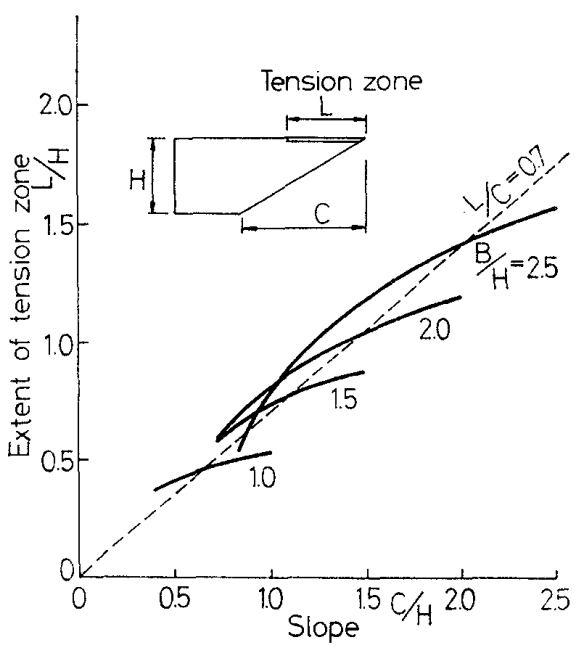

Fig. 3. The extent of the tension zone

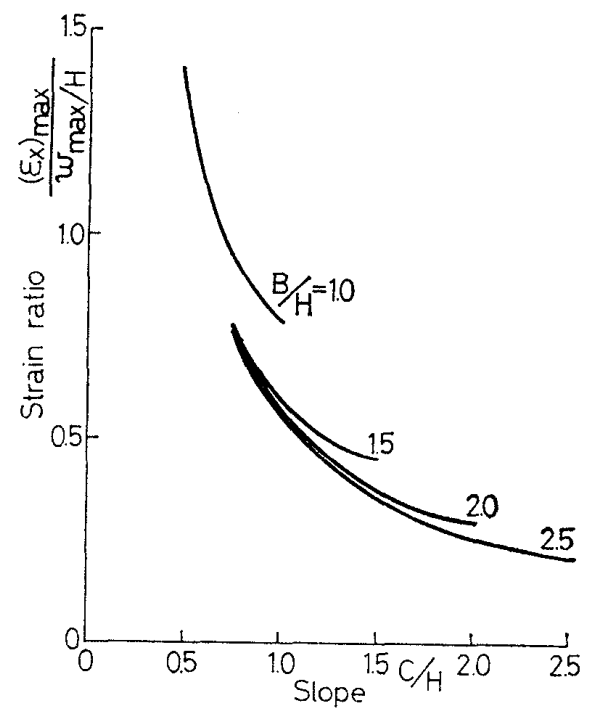

Fig. 5. Relation between the strain ratio and the inclination of the abutment

of tensile strain zone $L$ to the inclination of the abutment $C / H$ and the width of valleys $B / H$ are summarized in Figs. 3 through 5. Fig. 3 shows the relation between the normalized extent of the tension zone $L / H$ and the slope inclination $C / H$, in which roughly averaged linear relationship is drawn by a dashed straight line. It is seen that the extent of the tension zone depends mainly on the slope inclination and its magnitude is approximately $70 \%$ of the length $C$. The maximum strain $\left(\varepsilon_{x}\right)_{\max }$ is correlated to the parameters $B / H$ and $C / H$ in Fig. 4, showing that $\left(\varepsilon_{x}\right)_{\max }$ increases exponentially as the abutment slope gets steeper and is hardly influenced by the width of valleys. This relation is expressed in different form Fig. 5, in which $\left(\varepsilon_{x}\right)_{\max }$ is represented on the ordinate as a strain ratio to the vertical strain $w_{\max } / H$.

Fig. 6 shows three movement curves of $u, w$ and $\varepsilon_{x}$ along the crest of dams constructed 


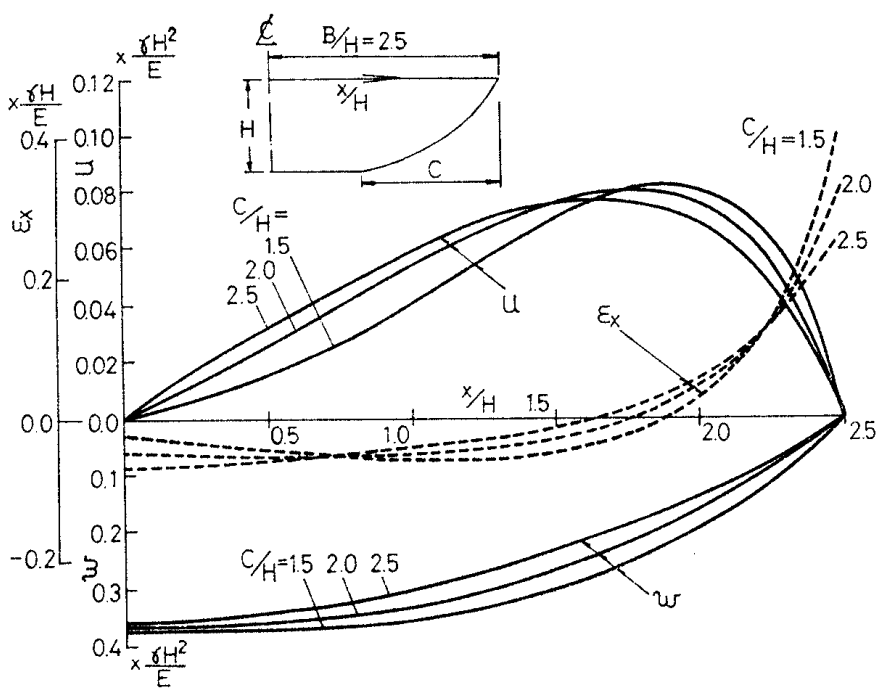

Fig. 6. Three movement curves along the crest of dams constructed in $\boldsymbol{U}$-shaped valleys $(\boldsymbol{B} / \boldsymbol{H}=$ 2.5)

in $U$-shaped valleys, in which shapes of the abutment are given by enlarging a quarter of a circle with radius $H$ in the horizontal direction. It is seen that, though both components of displacement are less influenced by the value of $C / H$ as compared with the case of trapezoidal valleys (Fig. 2), the horizontal strain $\varepsilon_{x}$ is still dependent on $C / H$ because it is susceptible to a little difference in the distribution of horizontal displacement. In this case, moreover, the horizontal strain is likely to have its maximum value near the core contact area of the crest where the abutment is locally steep, and therefore cracks or gaps could generate in that area.

Magnitudes and directions of major and minor principal stresses are plotted in Fig. 7 for different longitudinal sections of dams having the same values of $B / H$ and $C / H$ : in which the part of the crest enclosed by a dashed line stands for the tensile stress zone. It is recognized that rather severe situation for crack generation arises in the $U$-shaped section than in the trapezoidal one, tensile principal stress being larger near the core contact area and the tension zone reaching deeply. In the section c), where a sharp change of the inclination exists along the abutment at a point $0.6 \mathrm{H}$ above the base (the inclination is $i_{1}$ for the lower slope and $i_{2}$ for the upper one), the tension zone grows over considerably wide extent of the crest surface and larger tensile stress appears just above the turning point of slopes.

Fig. 8 shows contours of major principal strain developed in the same longitudinal sections of dams presented in Fig. 7. Numerical values denoted in the figures indicate those of normalized strain (tension is positive) and actual strain can be obtained by multiplying them by $r H / E$. In these contours, the tensile (positive) strain which appears to develop in areas where both components of principal stress are compressive signifies lateral expansion of a soil element accompanied by major principal stress acting almost vertically. On the other hand, tensile strain developed in the tension zones consists of strain accompanied by tensile principal stress acting almost horizontally and that due to lateral expansion. In all sections a) through c), concentration field of tensile strain appears in the crest part of the dam, in particular, larger tensile strains come out at the core contact in the $U$-shaped section. Note that, in section c), another concentration field appears in the vicinity of the turning point having almost the same magnitude of tensile strain as compared with that of the upper field. In actual dams, such a lateral expansion is often accompanied by the local reduction of minor principal stresses and sometimes contributes to internal crack- 

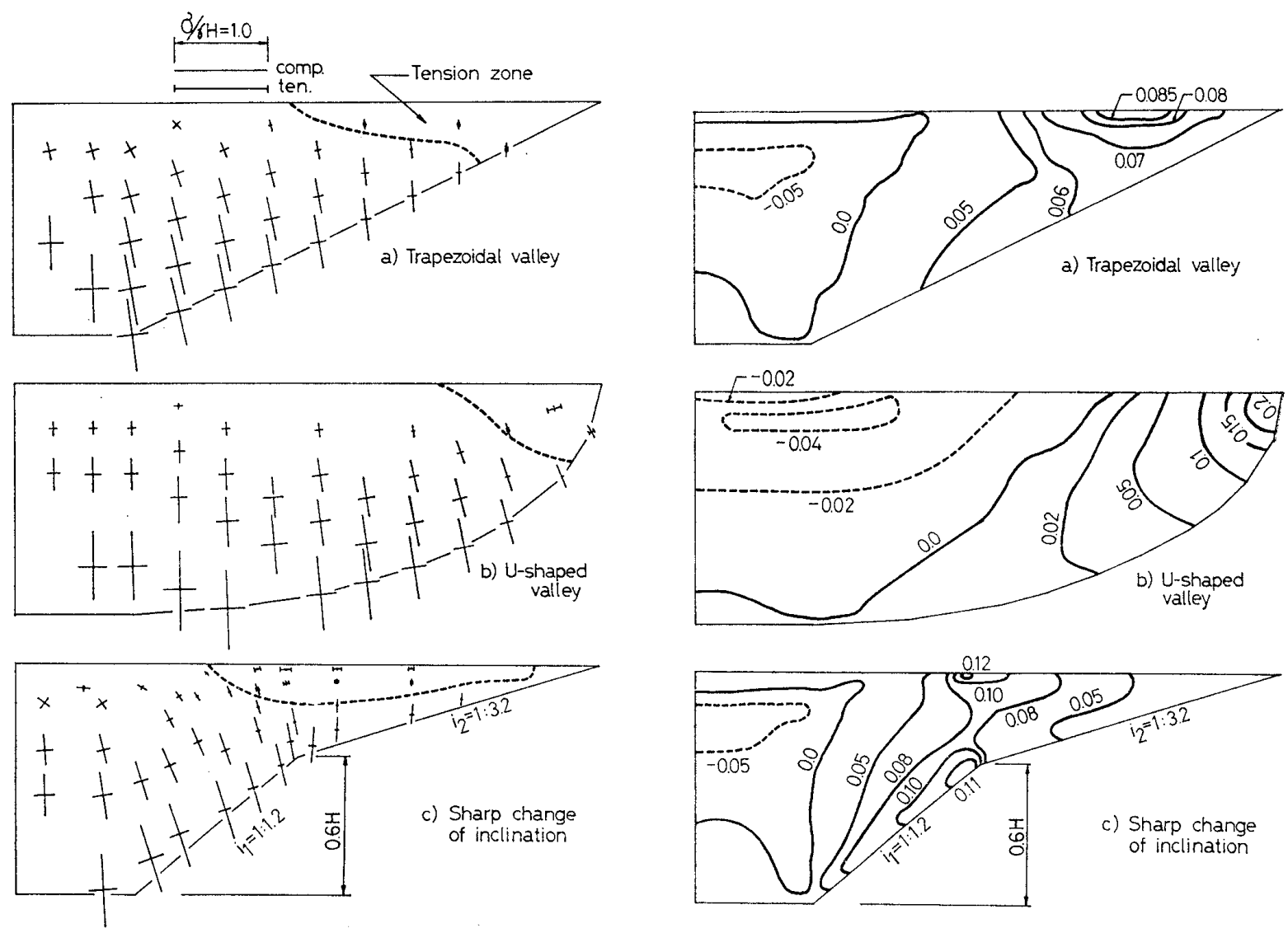

Fig. 7. Distrubutions of major and minor principal stresses $(B / H=2.5, C / H=2.0)$

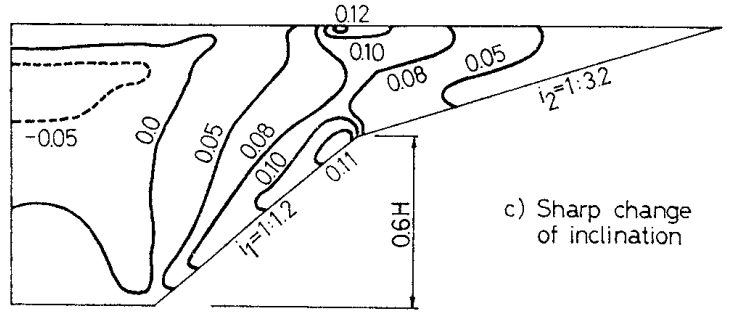

Fig. 8. Contours of major principal strain $(\boldsymbol{B} / \boldsymbol{H}=2.5, C / H=2.0)$

ing or hydraulic fracturing (Narita, 1976). The upper strain concentration field tends to develop just above the turning point as the change in slope get sharper.

The influence of the sharp change in slope on the distribution of tensile strain are summarized in Figs. 9 and 10. Fig. 9 shows the relation between the maximum tensile strain

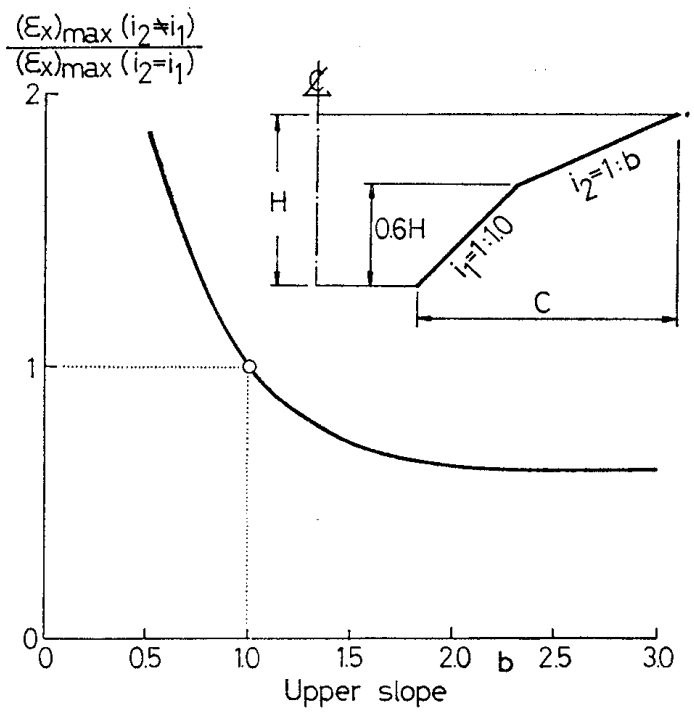

Fig. 9. The influence of the change in slope (lower slope constant)

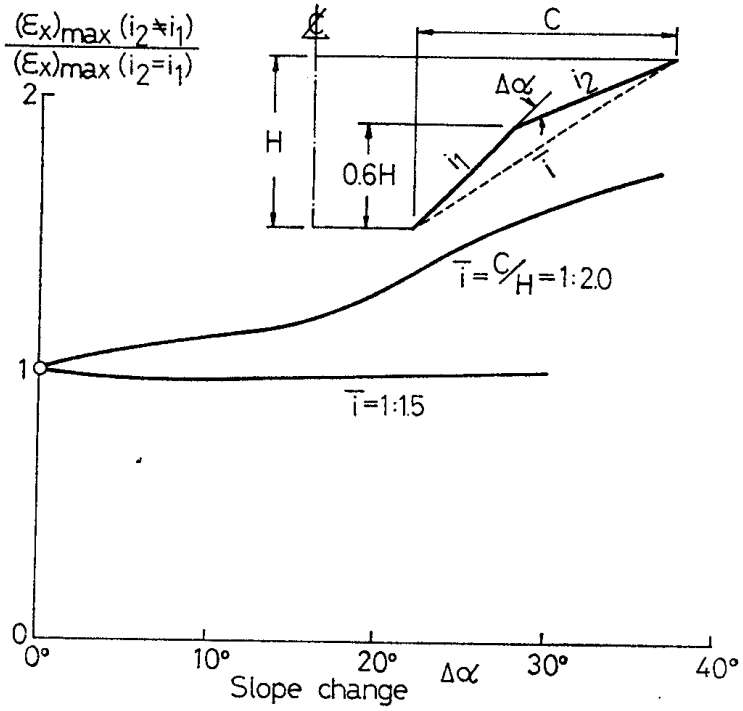

Fig. 10. The influence of the change in slope (average slope constant) 
developing at the crest and the upper slope $i_{2}$ when the lower one is fixed to be $1: 1.0$ slope. The ordinate indicates the ratio of the maximum strain when $i_{1} \neq i_{2}$ to that when $i_{1}=i_{2}$. It is noticed that, even if $i_{2}$ becomes greater (the change in slope gets sharper) beyond the bound $i_{1}=i_{2}$, the maximum tensile strain shows a decrease and that it increases abruptly as $i_{2}$ decreases being less than $i_{1}$. These tendencies suggest the fact that the tensile strain at the crest depends mainly on the average inclination of the whole abutment surface $C / H$ rather than on the magnitude of the slope change.

Similar relation is obtained in Fig. 10 when the slope change is given variety at the point $0.6 \mathrm{H}$ above the base while the average slope is fixed to be a specified value. In this case the difference of slope angle between the upper and lower slopes is taken on the abscissa in degrees. It is of interest to note that the increasing rate of the tensile strain due to the increase in $\Delta \alpha$ shows different tendencies according to the average slope $C / H$. The above fact will give a suggestion for controlling cracks in the practical design and construction that the average slope of the whole abutment also should be taken into account in making a limitation for the slope change, while only a limitation as $\Delta \alpha=20^{\circ}$ was set up in Mica dam (Webster, 1970).

Settlements or strains developing in an embankment may be classified as follows: i.e., those due to the placement of fill materials during construction and those resulting from: material consolidation or saturation after construction. As mentioned previously, the single lift analysis may be proper procedure for evaluating the latter deformations. On the other hand, for estimating the former deformations, the incremental loading procedure would be suitable because several satisfactory agreements with the observed settlement have already achieved when the material non-linearity was considered (Clough and Woodward, 1967 ; Kulhawy et al., 1969 ; Nakano et al., 1975). Fig. 11 shows contours of major principal strain within an embankment having $B / H=2.0$ and $C / H=1.5$, obtained by an incremental linear analysis. Comparing these contours and those of a single lift solution in Fig. 8a) to the distributions of the vertical displacement presented by Clough and Woodward (1967), it is recognized that each distribution pattern of principal strain resembles closely to the corresponding settlement pattern.

In assessing the possibility of crack generation, it may be concluded from the above that the tensile strain which is to be compared with the test results corresponds to the sum total of strains during and after construction obtained by both incremental loading and single lift analyses, though the summation requires some considerations on the consolidation

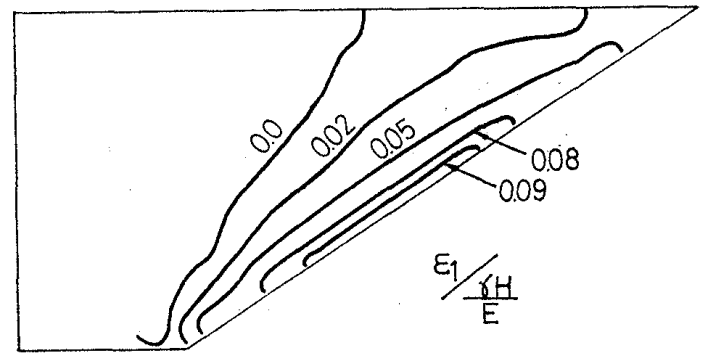

Fig. 11. Contours of major principal strain obtained by incremental loading analysis $(\boldsymbol{B} / \boldsymbol{H}=2.0, \boldsymbol{C} / \boldsymbol{H}$ $=1.5$ )

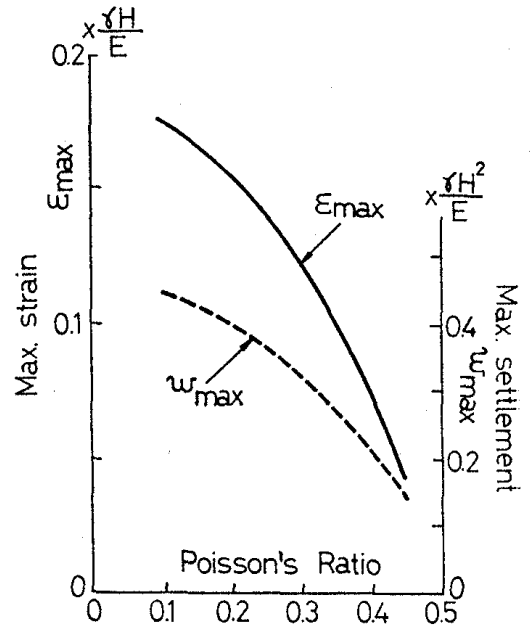

Fig. 12. The influence of Poisson's ratio 
characteristics of fill materials. Taking notice of the top portion of a dam, however, comparatively high rate of fill placing would be done, so that consolidation deformation in the lower part of the embankment due to the load applied at higher levels does not proceed so rapidly as to produce stress and strain redistributions within the top surface. It may be considered, moreover, that the state of a soil element immediately after it has suffered disturbance and subsequent compaction due to the running of heavy construction equipments corresponds to that of laboratory specimens prepared for compression and tension tests. In estimating the cracking potential of the top portion of the dam, it is therefore supposed reasonable to regard the state just at the end of construction as an initial condition of zero strain. Hence, for such an estimation, only the tensile strain after construction evaluated from the single lift solutions is useful for the comparison with the results of tension tests.

Finally, a brief comment on the influence of Poisson's ratio on elastic solutions is presented below. Fig. 12 shows the change in maximum tensil strain $\left(\varepsilon_{x}\right)_{\max }$ and maximum settlement $w_{\max }$ at the crest due to the change in Poisson's ratio: these are for a trapezoidal section having $B / H=2.0$ and $C / H=1.5$. It is seen that both settlement and strain decrease rapidly as Poisson's ratio increases. Take note now of the decreasing rate of settlement and strain due to the increase in Poisson's ratio. Considering, for example, when Poisson's ratio increases from 0.3 to 0.4 , the decreasing rate of settlement amounts to about $36 \%$ and that of strain about $40 \%$, showing almost the same magnitude between the two. This tendency suggests the fact that the ratio of the tensile strain $\left(\varepsilon_{x}\right)_{\max }$ to the vertical strain $w_{\max } / H$ defined in Fig. 5 is nearly constant for usual value of Poisson's ratio.

\section{PRACTICAL APPLICATION OF FINITE ELEMENT SOLUTIONS}

Rector Creek Dam (Leonards and Narain, 1963)

In order to apply the finite element solutions presented in the above section, the embankment profile was devided into two sections of which abutment surfaces were approximated by dashed straight lines (Fig. 13 a)). Solutions for trapezoidal valleys were then applied
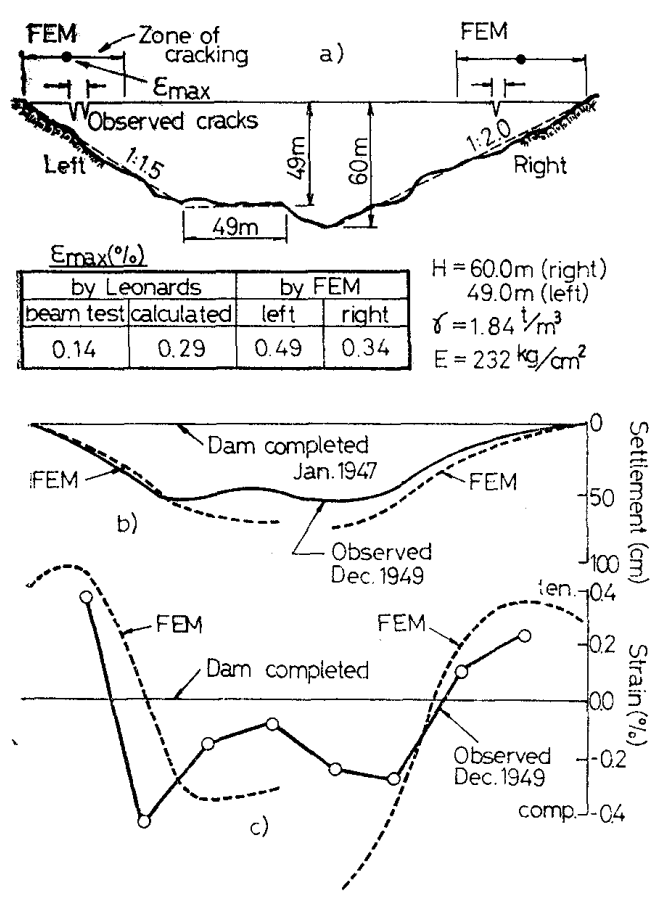

Fig. 13. Rector Creek Dam
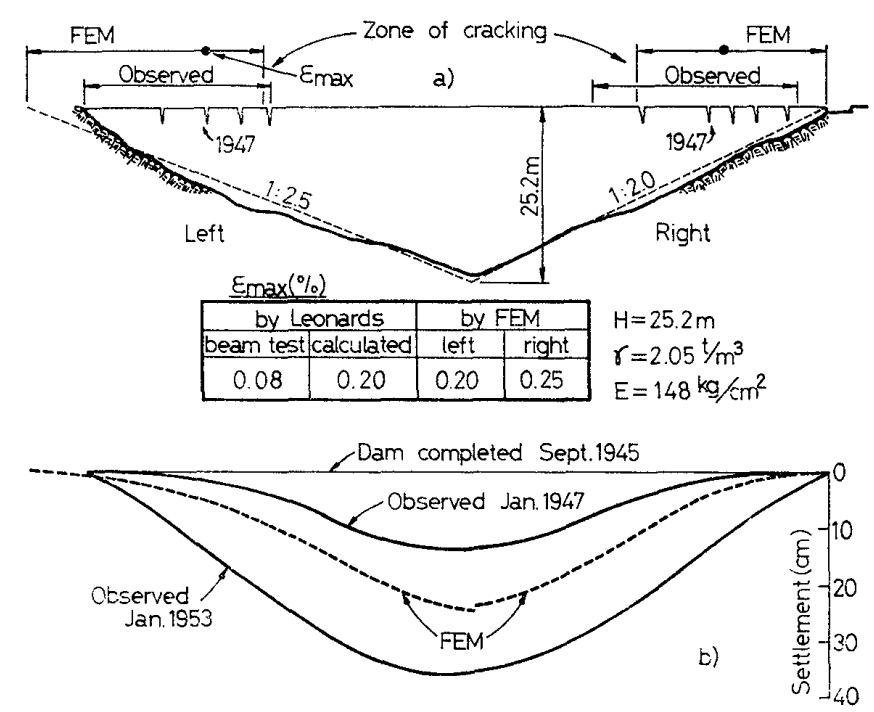

Fig. 14. Shell Oil Dam 
separately to both sections of the embankment:i.e., the left part is regarded as a half of $49 \mathrm{~m}$ high embankment with $B / H=2.5$ and $C / H=1.5$ and the right as a half of $60 \mathrm{~m}$ high embankment with $B / H=C / H=2.0$. Although the axis of symmetry of each section does not coincide with each other, the position of the axis need not be considered rigorously because crest movements are mostly influenced by the shape of the abutment. The value of $E$ and $\gamma$ used in numerical computations were referred to the properties of the embankment material as found ( $E$ from triaxial compression tests).

Maximum tensile strains at the crest computed by FEM are tabulated in Fig. $13 \mathrm{a}$ ), together with the tensile strains at cracking in the beam test and in the theoretical calculation presented by Leonards and Narain (1963). The position of maximum strains predicted by $F E M$ is also shown by solid circles. Furthermore, crest settlements and horizontal strains computed are given by dashed curves in Figs. $13 \mathrm{~b}$ ) and c) and these are compared with the observed movements after construction. The zone of cracking can be defined by the extent where the computed tensile strain exceeds the given cracking strain in the beam test and these are shown in Fig. 13 a).

Shell Oil Dam (Leonards and Narain, 1963)

The profile of the dam can be approximated by two halves of $25.2 \mathrm{~m}$ high $V$-shaped embankments. The magnitude and the position of the computed maximum tensile strains and the zone of craking are given in Fig. 14a). The computed crest settlements are compared with the observed in Fig. $14 \mathrm{~b}$ ).

El Infiernillo Dam (Marsal and Ramirez, 1967)

The embankment was approximated by two halves of a $148 \mathrm{~m}$ high $V$-shaped embankment with $1: 1.0$ abutment slopes (Fig. 15). For lack of pertinent data on the deformation modulus $E$ of fill materials, the value of $E$ was determined here for each section by equating the computed settlement with the observed at each axis of symmetry (Fig. $15 \mathrm{~b})$ ). The computed horizontal strains are compared with the observed strains at cracking in Fig. $15 \mathrm{c}$ ). The position of maximum tensile strains and the extent of the tension zone are shown in Fig. 15 a).

It is common to the above three dams that most of the settlement is caused by the saturation of fill materials when a reservoir was first impounded and that this rapid differential settlement is very conductive to the development of transverse cracks. As such a settlement is supposed to be due to the change of soil structures on wetting, it could be allowed from an analytical viewpoint to regard it as that caused by reduction in rigidity of the body of embankment under the line of seepage.

In the case of Rector Creek dam, the computed and observed settlements show considerably close
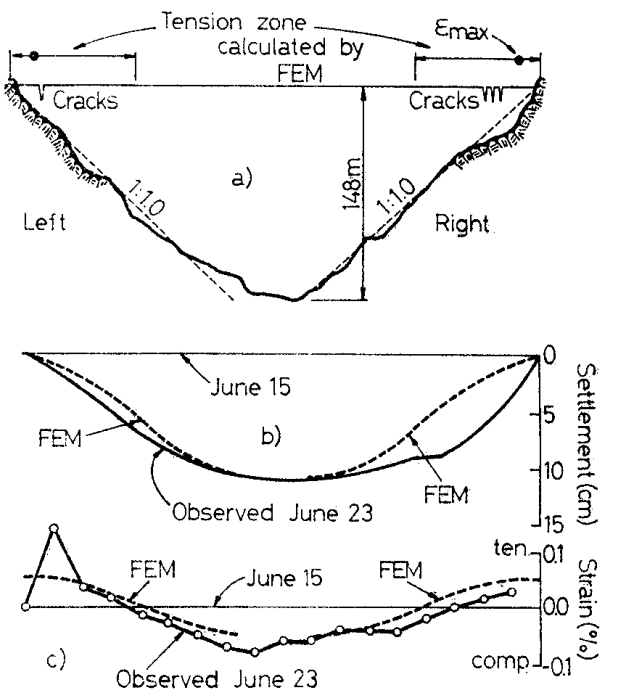

Fig. 15. El Infiernillo Dam agreement, particularly in the vicinity of the left abutment. As the result, it is recognized that satisfactory agreement between the computed and observed strains is attained both in magnitude and distribution, and that the position of maximum tensile strains corresponds closely with the position of transverse cracks. Similar good correspondence is also seen in the case of Shell Oil dam.

The deformation modulus $E$ used in the above computations was referred to the results 
from conventional triaxial compression tests. This parameter does not necessarily include such factors as express the reduction in rigidity of fill materials on wetting. However, it is evident in these case studies that, whichever phenomenon leads to the post-construction settlement, satisfactory prediction for the cracking potential of fill dams can be attained on the basis of finite element solutions if material parameters $E$ or $\nu$ are adjusted as the computed settlement be quated to the observed. Because the ratio of the tensile strain to the settlement is almost unchanged by the value of $\nu$, as stated before, it is rather convenient to let the modulus $E$ be varied in the adjustment. Further research is then needed in estimating the settlement after construction with good accuracy.

Calculated maximum strains presented by Leonards and Narain (1963) given in the tables: in Figs. 13 and 14 were obtained by applying the elastic theory to the observed settlement patterns. It is of interest to note that such a simplified approach also shows good correspondence to the observed movements, being by no means inferior to the finite element solutions. However, the proposed approach would have a limit in practical application for the prediction of the cracking potential because the configuration of actual abutment surfaces can not be considered.

In the case of $E 1$ Infiernillo dam, the modulus $E$ was determined by equating the computed settlement to the observed. The value of $E$ such determined shows about $7,300 \mathrm{~kg} /$ $\mathrm{cm}^{2}$ in magnitude and this is unconceivable for a deformation modulus of the core material. This is because of the observed settlement being very small as compared to the height of the dam. For one of interpretations on such a small settlement, it is stated that an: arching action might have occured in the core zone against the outer shells. Accordingly, it can be concluded that the above determined $E$ is not a deformation modulus of material itself but that of the whole structure of the embankment which involves some effects like arching action. It is of interest to note that, though further discussion is needed on the abovedefined $E$, close correspondence to the actual behaviours is noticed also in a rockfill dam.

\section{PROPOSAL FOR ASSESSING THE POSSIBILITY OF CRACKING}

Fig. 16 shows the relation between the tensile strain at the crest and the inclination of abutment slopes, in which the tensile strain is normalized by a dimensionless quantity $r H /$ $E$. Elastic solutions shown in Fig. 4 are now averaged and represented by a solid curve. for the reason that the width of valleys is hardly influential on the relationship. Observation results in actual dams presented by Justo (1973) are also plotted in solid and open circles. The former symbol is for the dam in which cracks occured and in this case tensile strain at cracking is taken for $\varepsilon$. In normalization of the observed strains, the elastic modulus resulted from oedometer tests on fill materials was used for $E$ being averaged in full height of the embankment and the material unit weight $\gamma_{t}$ was used for $r$. It is. recognized that observed relationships between the tensile strain and the inclination are: close to the elastic solutions. Concerning with the fact that the curve for elastic solutions. overlies far from the observed results, following aspects can be considered.

From a viewpoint of consolidation phenomenon, the total settlement $w_{t}$ which might occur throughout a life of a dam may be represented in general as

$$
w_{t}=w_{0} r H^{2} / E
$$

in which $\gamma, H$ and $E$ denote the material unit weight, the height of the dam and the modulus of elasticity resulting from oedometer tests, respectively. The symbol $w_{0}$ denotes a constant coefficient which varies with both Poisson's ratio of soil and the configuration of valley. Provided that the degree of consolidation amounts to $U$ during construction, a part of the total settlement which may develop after construction $w_{a}$ can be represented in the following form: 


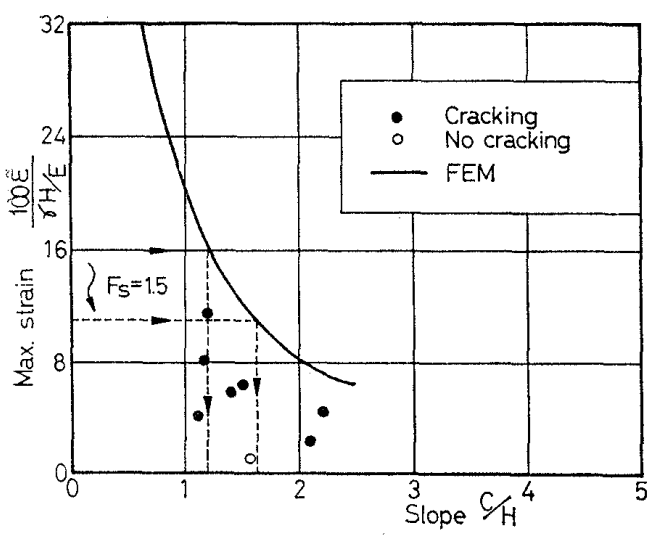

Fig. 16. Assessment of the cracking potential (I)

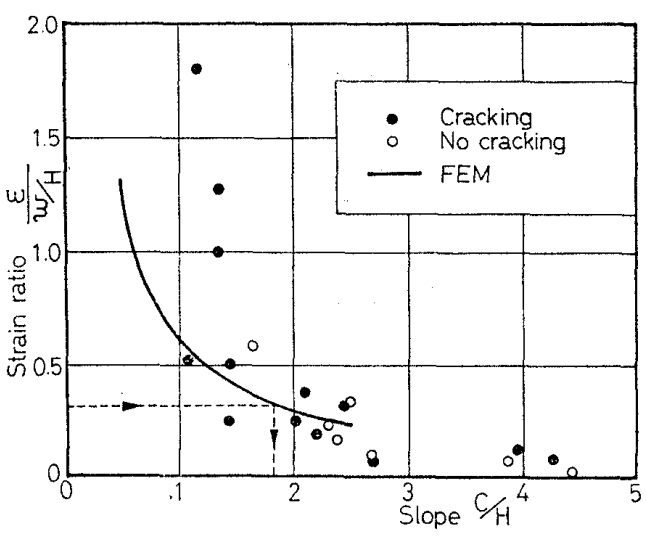

Fig. 17. Assessment of the cracking potential (II)

$$
w_{a}=A w_{t}=A\left(w_{0} \gamma H^{2} / E\right), \quad A=1-U / 100
$$

in which the coefficient $A$ is considered empirically to be in the range from 0.1 to 0.4 , and a method of quantitative estimation of $A$ for various types of dams has been already proposed by Yamaguchi and Ohne (1973).

The modulus of elasticity from oedometer tests used in the arrangement of the observed data in Fig. 16 may correspond to the total settlement $w_{t}$ in Eq. (1). Hence in view of the fact that the observed strains have developed corresponding to the settlement after construction, this modulus of elasticity is required to be adjusted by an amount worth the degree of consolidation after construction. Namely, as Eq. (2) can be rewritten in the form :

$$
w_{a}=w_{0} \gamma H^{2} /(E / A)=w_{0} \gamma H^{2} / E_{a}, \quad E_{a}=E / A
$$

it is supposed that normalized strains will increase and result in better correspondence to elastic solutions if $E_{a}$ is used for $E$ in place of the modulus of elasticity from oedometer tests.

The ordinate in Fig. 16 was replaced by the ratio of the tensile strain $\varepsilon$ to the vertical strain $w / H$ as shown in Fig. 17, in which $w$ denotes the crest settlement after construction at the central axis of an embankment. The solid curve indicated is that of elastic solutions shown in Fig. 5 being averaged. Many observed data can now be plotted as the strain ratio was adopted, because intermediate troublesome steps of estimating average modulus of elasticity can be cut out in the arrangement. Except for a few data in the extent where the abutment slope is steep, elastic solutions show comparatively good correspondence to the observed results, both in cracking and no cracking cases.

Such a good correspondence confirms that elastic solutions are sufficient for practical use, together with appropriate estimation of $E_{a}$ or $w_{a}$, to evaluate tensile strains developing at the crest after construction. The possibility of cracking can then be examined by comparing the predicted tensile strain with the material cracking (failure) strain from pure-tension tests. For this purpose, curves shown in Figs. 16 and 17 can be used effectively in the following manner.

Consider a hypothetical example of a $50 \mathrm{~m}$ high dam, constructed of material having $\gamma=2.0 \mathrm{t} / \mathrm{m}^{3}$ and $E=100 \mathrm{~kg} / \mathrm{cm}^{2}$ (from oedometer test), as a model case. When it is assumed to have a coefficient $A=0.25$, the dimensionless quantity in Eq. (3) for the post-construction deformation shows $\gamma H / E_{a}=0.025$. Hence, if pure-tension tests on the material resulted in a cracking strain $\varepsilon_{t}=0.4 \%$ refering to the test results on a silty sample compacted at the optimum water content (Narita, 1976), a critical condition in which $\varepsilon=\varepsilon_{t}$ would get a normalized strain to have 16. As is illustrated in Fig. 16, this strain yields a critical 
requirement that the abutment slope should not be steeper than $1: 1.2$ slope for this dam. It should be considered the factor of safety $F_{s}$ in the practical design. When a factor $F_{s}$ $=1.5$ is required, allowable strain with which the predicted tensile strain is compared becomes to $\varepsilon_{t} / F_{s}=0.27 \%$ and the ordinate indicates about 11 . As the result, it is recommended to excavate the abutment not to be steeper than around $1: 1.6$ slope.

Such assessment is also useful when the abutment slope is prescribed beforehand. In this case, it will be decided how much of the cracking strain should be hold to keep a margin of safety for crack generation.

In practice, however, it demands much effort to control the cracking strain of placingmaterial and, even if feasible, another aspect of crack generation associated with tensile strength should be considered. For this reason, appropriate measures such as adjustment of the rate of construction or proper arrangement of drainage zones would be adopted practically in order to promote dissipation of remained porewater pressure and to limit settlement after construction.

The material Poisson's ratio $\nu$ is very influential factor on the relation in Fig. 16 because the tensile strain showed a serious change due to the variation of $\nu$ (Fig. 12). The solid curve indicated, which is so to say equivalent to a critical line of crack generation, is for elastic solutions when $\nu=0.3$. Then, for greater values of $\nu$ than 0.3 , critical lines will be drawn under the curve for $\nu=0.3$ due to the decrease in the tensile strain. Hence, the critical line for $\nu=0.3$ is on the safe side than those for $\nu>0.3$ in the prediction of the cracking potential.

To avoid some troublesome errors due to the effect of Poisson's ratio, the application of the relation in Fig. 17 would be more valid for practical use. This is because, as is stated before, the strain ratio on the ordinate is hardly influenced by this parameter. Similar procedure may be adopted in the assessment of the cracking potential. For previously stated mocel dam, the settlement after construction can be determined from Eq. (2) as $w_{0}=0.5$ and $w_{a}=0.625 \mathrm{~m}$ regarding the dam as a rectangular soil prism. The vertical compressive strain $w_{a} / H$ then becomes equal to $1.25 \%$ and it gives a critical strain ratio of 0.32 when $\varepsilon=\varepsilon_{t}=0.4 \%$. As the result, the examination of the relation provides around $1: 1.8$ slope as a critical slope of the abutment. This critical slope somewhat differs from that determined before, because settlement was calculated here for a rectangular prism without consideration of boundary conditions and the critical lines in Figs. 16 and 17 were drawn to produce most appropriate average lines individually.

Fig. 17 would ke also useful for evaluating the present con-

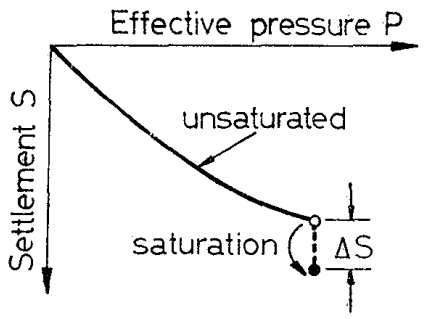

Fig. 18. Settlement increment due to saturation dition of the stability for cracking on the basis of field observations of the crest settlement after construction. Furthermore, as a reverse consideration, a limit of the crest settlement which is required to maintain some margin of safety for cracking could be determined.

As the above discussions were only concerned in consolidation settlement, following treatments are recommended for the case in which most of the settlement is caused by the saturation of fill material. It has often been experienced that a soil specimen which has already been consolidated in 100\% maintaining unsaturated state shows an increase in settlement (or compressive strain) when it is submerged (Fig. 18). In such a case, additional compressive strains which develop in soil elements within the body of an embankment after they are saturated lead to the postconstruction settlement at the crest. Hence, it would be more proper to predict the cracking potential by considering that this incremental strain corresponds to the vertical strain $w / H$ in Fig. 17. 
Thus, in the application of the relation shown in Fig. 17, it is a matter of great concern how the post-construction settlement can be evaluated precisely. Two methods of estimating consolidation settlement have been presented by Narita (1976). Concerning with the settlement at reservoir filling, such a reliable method as express actual phenomenon of compression has not yet been presented in the present time. As a conventional method, Lee and Shen (1969) proposed an useful approach in which the settlement accompanied by a rise of the reservoir level is represented by the difference of settlements which are calculated for a dam but with two different water levels.

Finally, the material non-linearity is a matter of great importance for rigorous discussion of the cracking problem. Some examinations were given on this respect by Narita (1976) introducing non-linear tensile stress-strain characteristics of soils. As one of major results, it was noticed that non-linearity on the whole increased the tensile strain at the crest as compared with linear solutions. This signifies that elastic solutions somewhat tend to estimate the possibility of cracking on unsafe side. Further comprehensive study is still required before a precise method of assessing the possibility of cracking is established, especially concerning non-linear stress-strain redistributions in embankments after construction.

\section{CONCLUSIONS}

Concluding remarks drawn from the present study are summarized in the following.

(1) Tensile strain which develop after construction in the crest part of dams are largely influenced by the configuration of abutment surfaces, especially by the inclination of abutment slopes.

(2) Some case studies suggest that the finite element elatsic solutions are very effective for the prediction of the cracking potential in actual dams.

(3) The proposed method of assessing the possibility of crack generation is useful for predicting and controlling transverse cracks in the practical design and the construction of fill-type dams.

\section{ACKNOWLEDGEMENT}

The authors wish to express their gratitude to Prof. Hakuju Yamaguchi of Tokyo Institute of Technology for his guidance in this study. Numerical computations in the present study were made by use of the digital computer FACOM 230-60 at the Computer Center, Nagoya University.

\section{NOTATION}

$A=$ coefficient related to post-construction settlement

$B=$ half of the crest length

$C=$ length of horizontal projection of the abutment

$E=$ modulus of elasticity

$E_{a}=$ modulus of elasticity defined by Eq. (3)

$F_{s}=$ factor of safety

$H=$ height of dam

$i_{1}, i_{2}=$ lower and upper slope inclination

$L=$ extent of the tension zone

$u=$ horizontal displacement

$u_{\max }=$ maximum horizontal displacement

$w=$ vertical displacement (settlement) 
$w_{\text {max }}=$ maximum settlement

$w_{t}, w_{a}=$ total and post-construction settlement

$w_{0}=$ coefficient related to the crest settlement

$\varepsilon_{x}=$ horizontal strain

$\left(\varepsilon_{x}\right)_{\max }=$ maximum horizontal strain

$\varepsilon_{t}=$ tensile strain at cracking

$\varepsilon_{1}=$ major principal strain

$\gamma, \gamma_{t}=$ unit weight of soil

$\nu=$ Poisson's ratio

\section{REFERENCES}

1) Clough, R. W. and Woodward, R.J. (1967): "Analysis of embankment stresses and deformations," J. Soil Mech. Found. Div., ASCE, Vol.93, No. SM 4, pp. 529-549.

2) Covarrubias, S. W. (1969): "Cracking of earth and rockfill dams," Harvard Soil Mech. Series, No. 82, April.

3) Eisenstein, Z., Krishnayya, A. V.G. and Morgenstern, N. R. (1972): “An analysis of cracking in earth dams," Proc. Symposium on Applications of the Finite Element Method in Geotechnical Engineering, Vicksburg, Mississippi, pp. 431-455.

4) Justo, J. L. (1973): "The cracking of earth and rockfill dams," 11th Int. Congress on Large Dams, Madrid, pp. 921-945.

5) Kulhawy, F.H., Duncan, J.M. and Seed, H. B. (1969): "Finite element analyses of stresses and movements in embankments during construction," U.S. Army Engineers Waterways Experiment Station, Corps of Engineers.

6) Lee, K. L. and Shen, C.K. (1969): "Horizontal movements related to subsidence," J. Soil Mech. Found. Div., ASCE, Vol.95, No. SM 1, pp. 139-166.

7) Leonards, G. A. and Narain, J. (1963): "Flexibility of clay and cracking of earth dams," J. Soil Mech. Found. Div., ASCE, Vol.89, No. SM 2, pp. 47-98.

8) Marsal, R. J. and Ramirez de Arellano, L. (1967): "Performance of El Infiernillo dam, 19631966," J. Soil Mech. Found. Div., ASCE, Vol.93, No. SM 4, pp. 265-298.

9) Nakano, R., Tanaka, T. and Yamashita, S. (1975): "Finite element analysis of stresses and deformations of Miyama dam," Tsuchi-to-Kiso, JSSMFE, Vol.23, No.1, pp.19-26 (in Japanese).

10) Narita, K (1976): "On the mechanism of crack generation in fill-type dams," Doctoral thesis submitted to Tokyo Institute of Technology, December (in Japanese).

11) Sherard, J. L., Woodward, R. J., Gizienski, S.F. and Clevenger, W. A. (1963): Earth and Earth -Rock Dams, John Wiley \& Sons.

12) Webster, J.L. (1970): "Mica dam designed with special attention to control of cracking," 10 th Int. Congress on Large Dams, Montreal, pp. 487-509.

13) Yamaguchi, H and Ohne, Y. (1973): Design and Construction of Fill Dams, Giho-do (in Japanese).

(Received April 20, 1977) 